\title{
Challenge in Artistic Flow Experiences: An Interdisciplinary Intervention
}

\begin{abstract}
This paper explores the psychological phenomenon of flow through a nonrepresentational geographical emphasis on material practices. Both the positivity and skillschallenge balance assumed to characterise flow are brought into question by the challenge and negative feelings arising from material aspects of artistic practice. This challenge appears to be localised around a pivotal point in the emergence of the artwork, and essential for both successful completion of the artwork and experience of flow. This localisation is conceived as a period of chimerical instability in the ontological status of the artwork, during which the artwork is more than a series of marks but not yet a finished work, and a zone of indiscernibility concerning when activity should cease. Particular features of material practiceheterotechnicity or cooperative framework, and heterochrony or magnification of effects from small scale changes - provide a means of re-thinking the skills-challenge relationship in artistic flow experiences.
\end{abstract}

\section{Keywords}

flow; artistic practice; skill; challenge; non-representational thinking

\section{Introduction}

This paper draws upon a certain feature of non-representational thinking-material agency - to interrogate the experience of flow, in an activity in which both material agency and flow have been reported: artistic practice. It develops previous research (details removed for peer review), which highlighted greater attribution of artistic control by artists to their materials among artists working in two-dimensional media (e.g. drawing and painting) than those working in three-dimensional media (e.g. pottery). I focus here on the experiences of artists 
working in two-dimensional media to explore the role of materiality in artistic flow experiences in greater depth, drawing together psychological and geographical interests and methods through a non-representational focus on material practice.

Non-representational thinking replaces a preoccupation with representation with a processual and eventful emphasis on how we bring the world into being and adopts a wider, post-humanist account of life that recognizes more-than-human agency (Anderson and Harrison, 2010, Dewsbury, 2010a, 2010b, Greenhough, 2010). This gives rise to a world and life affirming philosophy in which human and non-human alike emerge in processes of becoming (McCormack, 2010) and which emphasizes the radical contingency of the subject (Anderson and Harrison, 2010, Banfield, 2016). Simply defined, flow is intrinsically enjoyable and is characterized by total immersion in an activity, along with a loss of self-awareness and a sense of self-validation (Privette, 1983, Csikszentmihalyi, 1996, 2002, Bakker, 2005), and is of particular interest to positive psychology, which is concerned with productive and exceptional rather than pathological aspects of human life (Maslow, 1971, Joseph and Linley, 2008, Schneider, 2011). Specifically, the lack of awareness of self as separate from activity and sense of union with the world reported to occur in flow (Csikszentmihalyi, 2002) bear traces of affective and affirmative rather than solely representational or cognitive connectivity with the world (McCormack, 2010). This, together with alterations in the perception of time in flow, in which the orderly progression of clocks is rendered irrelevant by the rhythms dictated by the activity (Csikszentmihalyi, 2002), suggests that voluntary engagement with activities conducive to flow can be considered a means of manipulating time in practices with force before and beyond reflection (McCormack, 2003). Thus, flow can be considered a disruptive continuity as artists fall in and out of step with the march of their artistic environment (Dewey, 1934), into which artists repeatedly replace themselves to re-establish the rhythmic pattern (Bachelard, 2000) of flow. Consequently, the similarities between the qualities of experience 
associated with flow and features of non-representational thinking present a tantalizing opportunity to consider how these two avenues can work productively together.

Two often-cited characteristics of flow are a positive emotional state such as pleasure or enjoyment, and a balance between the challenges faced in the activity and the skills available to tackle them (Csikszentmihalyi, 1975a, 1975c, 1991, 1996, Csikszentmihalyi and Robinson, 1990, Privette, 1983, 2002, Bakker, 2005, Zaman et al., 2010, Kaltwasser Hamilton et al., 2018). However, some literature challenges these defining characteristics. Some studies have reported participant accounts of flow during activities that featured negative emotional states, such as feeling terror in dangerous pursuits or anxiety in the face of performance failure (Lipscombe, 1999, Walker and Burgess, 2011), while more recent work has proposed that the experience and expression of anger during heavy metal performances is part of what makes the performance enjoyable and generates flow (Kaltwasser Hamilton et al., 2018). Indeed, the recognition that flow can occur in the face of adversity (Csikszentmihalyi, 2002) suggests that in at least some instances the experience of negative feelings arising from such circumstances is constitutive of the experience as flow.

Challenge and skill have been described as the two most theoretically important dimensions of flow (Csikszentmihalyi, 1991), so understanding the relationship between them is important to understanding flow. While a balance or match between skills and challenge is commonly proposed in literature on flow, the ways in which these terms have been operationalised vary (Zaman et al., 2010). Within Csikszentmihalyi's own writings, this "golden ratio between challenges and skills" (Csikszentmihalyi 2002: 52) has been variously described as a balance between being in control and being overwhelmed (Csikszentmihalyi, 1975a), between the skills or ability to act and the opportunities for action (Csikszentmihalyi, 1975a, 1991, 1996, 2002) or between the perception of skills and challenges which may occur retrospectively following the experience rather than during the activity (Csikszentmihalyi, 
1975c). Elsewhere the balance between challenge and skills has been associated not with being in control but with exercising control (Csikszentmihalyi, 1991) in difficult situations, or with the possibility rather than actuality of control and the lack of worry about losing control (2002, Csikszentmihalyi, 1975c). In some of these accounts, the important factor seems to be a lack of fear of failure (Csikszentmihalyi, 1996, 2002) whereby a successful outcome is certain. In other cases, challenge and skill are deemed to be nearly in balance (Csikszentmihalyi and Robinson, 1990) such that there is a chance of completing the challenge faced (Csikszentmihalyi, 1991) but a successful outcome is not guaranteed. In yet other circumstances, the balance between skills and challenge is reported to be such that an individual is stretched to the limit of their abilities and a successful outcome is doubtful (Csikszentmihalyi, 2002).

Given these reports of negative aspects of flow experiences and a skills-challenge uncertainty (Lipscombe, 1999, Walker and Burgess, 2011, Banfield and Burgess, 2013), the stretching to the limit of or beyond one's perceived abilities seemingly provides the most fruitful way in which to construe the golden ratio between skills and challenge. This is more in keeping with Csikszentmihalyi's view that people cannot enjoy doing the same activity at the same level for long (Csikszentmihalyi, 1991), and with his emphasis on the centrality of problem finding as opposed to problem solving in creativity, which entails a possible lack of any immediate criteria for assessing progress (Csikszentmihalyi, 1975b). In contrast to the assertion that flow usually occurs in activities that provide clear, unambiguous feedback (Csikszentmihalyi, 1975c), the ambiguity or total lack of assessment criteria in many creative practices remains consistent with descriptions of flow activities if the challenge-skill relationship is one that is stretched or uncertain rather than balanced and predetermined. This perspective gains added weight in light of the acquisition of a sense of mastery that is proposed not only to occur with flow experiences (Csikszentmihalyi, 2002) but is said to be a basic 
assumption of the experience of flow (Csikszentmihalyi and Robinson, 1990). If flow occurs between boredom and anxiety (Csikszentmihalyi, 1975a) and flow brings mastery, it makes sense for skills to be stretched in order for flow to occur. It seems to me that if the outcome is certain then it is unlikely that flow will bring mastery, as the individual concerned must already have mastered the skills necessary to meet the challenge and must be aware of their capacity to do so for the outcome to be certain in advance, which would eliminate the challenge that would otherwise bring mastery if successfully met. Seemingly, then, the notion of flow bringing mastery in its wake makes sense only in the context of stretched abilities or skills (associated with an uncertain outcome), which is also consistent with assertions that it is the challenge that leads to the focusing of attention on the activity at hand (Csikszentmihalyi and Robinson, 1990, Csikszentmihalyi, 2002). This stretching brings uncertainty of outcome and with it fear of failure, subsequent to which ensues effort to extend one's abilities, grappling to achieve that which has not previously been achieved but which if achieved brings mastery.

Foregrounding challenge and the stretching of skills in flow leads us to consider the source of challenge in different flow activities. In some activities the source of challenge is clear, such as the danger inherent in skydiving, but in artistic practice the picture is somewhat murkier. Previous research (details removed for peer review) comparing artists working in twodimensional media (e.g., painting) and those working in three-dimensional media (e.g. woodturning), suggested that the latter were confident in evaluating their skills but less so the challenge they faced, while the former struggled to evaluate either, due to the different attributions of control in the artistic process and the different function served by feedback between these two groups of participants. Specifically, participants working in twodimensional media attributed control to their materials rather than themselves and considered feedback on their work to be formative rather than affirmative, as opposed to those working in three-dimensional media. Together, these features made the evaluation of both challenges and 
skills problematic for participants working in two-dimensional media. While recognising that this distinction is not exact, I adopted the same distinction in the current research and focused on artists working in two-dimensional media to explore this perceived material agency further.

After outlining my research method, I outline briefly the common structure of the artistic flow experiences of participating artists, before exploring and elaborating these features more thoroughly in the discussion. I describe the frustrations and challenges articulated by participating artists in relation to artistic flow experiences, and how the uncertain relation between skills and challenges is localised within artistic practices to a period of instability in the emergence of an artwork around a pivotal point, at which the work is considered complete but which frequently eludes prediction and identification. Here, I introduce two notions. The first is a period of chimerical instability during which the artwork is no longer a series of incoherent marks but has not yet been ruined by overworking, but neither is it considered complete. The second is a zone of indiscernibility, during which the identification of the pivotal point - the point at which if activity ceased the work would be complete-is elusive. The coincidence of these two notions is associated with the ontological realisation of the artwork as a completed work, and the sense of self-validation on the part of the practitioner.

Subsequently, the role of non-human actants in the negotiation and resolution of this instability is detailed, along with its necessity to both the successful outcome of the artistic practice and the experience of flow through the challenge generated by the instabilityindiscernibility nexus. In particular I focus on characteristics of heterotechnicity-a heterogeneous cooperative framework (Reynolds, 1994) - and heterochrony-profound differences arising from small changes (Kozbelt, 2009) — as defining characteristics of these material aspects of artistic practice. Finally, I conclude that the characterization of flow activities in terms of heterotechnicity and heterochrony enables us to understand better the varying relations between skills and challenges in different experiences of flow. 


\section{Research Method}

This study develops previous research (details removed for peer review) in which artists working in two-dimensional media (e.g. painting) were found to attribute artistic control to their materials to a greater degree than artists working in three-dimensional media (e.g. woodturning), focusing on artists working in two-dimensional media to explore this perceived material agency further. Although the previous study produced a phenomenological account of artistic flow experience, the current study is informed by non-representational geography's characterization as post-phenomenological, concerned less with the essences of an experience than the conditions for the emergence of those essences (Simpson, 2009, Ash and Simpson, 2016), and also by its conceptual and methodological focus on material practices and the prereflective (Anderson and Harrison, 2010, Dewsbury, 2010a). Reflecting this shift in emphasis, the research design was loosely phenomenological in nature but supplemented conventional retrospective interviews with real-time artistic practice sessions to generate more immediate accounts of artistic practice as it unfolded and to elicit potentially fuller accounts of experiences of flow during artistic practice.

\subsection{Data collection}

Preliminary interviews with each participant lasted approximately 30 to 90 minutes, and covered topics including the participant's artistic background, practices, products and experiences. Rather than asking directly about challenge in their artistic practice, I asked participants to tell me about their artistic practice in a general sense, to talk to me about the tools and materials that they use, and to describe different occasions when their artistic practice came closest to their ideal and fell short of that ideal.

Practice-based sessions lasted approximately two hours and entailed both researcher and participant engaging in artistic practice while discussing that practice, enabling close 
observation of the phenomenon under investigation by participation in the lifeworld of the participant (Van Manen, 1990). Two such sessions were held with each participant, sometimes individually and sometimes in small groups. These sessions sought to capture the life experience of artistic practice from within that experience, during which a shift from reflective to pre-reflective self-consciousness might occur, making participants' pre-reflective selfawareness more immediately available for reflection than in a conventional interview (Zahavi, 1999, 2005). In addition, both researcher and participants at times used artistic media and materials that differed from those that they would normally use to provide a source of comparison. By prompting awareness and consideration of how things might be done differently - a practical interpretation of imaginative variation - this intervention was designed to bring to participants' awareness aspects of their practice of which they might not normally be aware during their practice (details removed for peer review).

Closing interviews were sometimes held individually and sometimes as a group. During these interviews, general questions concerning research experiences were common across participants, for example asking how they had found the research process and asking about anything that had surprised participants, while questions concerning emergent issues and video footage were tailored to individual participants, such as asking participants to reflect on footage of their practice during which they remained vocally silent, or where the pace or nature of their practice suddenly changed. All interviews were voice recorded; those held during practice were both voice and video recorded. All voice recordings were transcribed verbatim.

\subsection{Data analysis}

Each transcript was read for the first time in its entirety to get a sense of the account overall, before a second reading in which changes of meaning were identified within the transcript and the meaning within each section or unit of text identified was summarised. A full 
list of themes that emerged from the analysis was produced, and the differences in articulated meaning between these themes in the accounts of the different participants enabled both a consolidation of themes into a smaller number of common structures or features of experience and a sense of the different experiences of each participant.

Video recordings of the production sessions were analysed in a manner parallel to that of the transcripts, with an initial viewing in full in advance of a second viewing that sought to identify characteristic or 'meaningful' actions, speeds and styles of mark-making. This generated a sense of actions and styles of practice that were both characteristic and uncharacteristic for a participant in a particular session. Extracts of visual data, which collectively covered both the characteristic and uncharacteristic practices of that participant were then selected for use in the participant's closing interview, to prompt further reflection on their artistic practices and associated flow experiences.

\subsection{Participants}

All participants lived locally to Oxford, England, and were identified and accessed via promotional materials for an annual arts festival. Of the twelve practising artists (aged 36 to 71), two identified themselves as hobbyists, two could be considered early career artists (within the first five years of professional practice) and the remaining eight were established professional artists.

Three artists participated on an individual basis. Jane (age 71) has retired from a career in art education. She uses a variety of media, and her work often depicts landscapes or scenery. Laura (age 36) is establishing her art career in Oxford, which involves practice, exhibition and teaching, following a previous career in publishing. Laura works primarily in oils and describes her work as being semi-abstract and about the spirit of place. Katherine (age 59) is an 
established artist who often works in situ, painting landscapes and scenery in watercolours, although she also works more abstractly when in her studio.

Three participants held their production sessions and closing interview as a group. Philippa (age 66) is currently establishing her practice in Oxford following a teaching career, and says that she likes to paint people, mainly in watercolour and oils. Yoko (age 61) has no formal art training but took up art as a hobby at the age of 36, and works with watercolour, pencil, charcoal and pen. Marnie (age 50) took up art after retiring from business and has attended a variety of courses since. Marnie's medium is soft pastels, although like Yoko she does not exhibit or sell her work.

Three further participants were recruited as a group, all of whom work in textiles, but two of these participants withdrew from the research. Polly (age 62) taught art for 35 years and took up her own practice upon retirement. Polly says that she likes the flexibility of textiles and much of her work is inspired by colours of India.

The final three artists held their production sessions collectively, as they routinely work together on a project trying to capture dance in painted form (details removed for peer review). In addition, each artist pursues their own studio-based practice. Susan (age 57) worked as an illustrator before committing to her own practice approximately 20 years ago. Susan works in mixed media such as print, paint and jewellery, producing work that she says is inspired by her life experiences. Clare (age 58) initially worked as a film editor and researcher before embarking on her artistic career, which employs oils, printmaking and watercolour. Kassandra (age 64) has both taught and practiced art in her career and her primary media are drawing, painting and printmaking. 
In the analysis that follows, the sources of the quotations used are indicated following the extract, identifying whether the session was a conventional interview ("I") or a practicebased interview ("P"), and whether it was the first or second of such sessions.

\section{Results}

The common themes that emerged from the analysis were:

1. an experience of struggle or challenge during artistic practice, associated with uncertainty as to the outcome;

2. the affective power of this struggle, involving self-doubt, anxiety and a desire to cease or destroy the work;

3. a material emphasis within this struggle, articulated as a non-verbal negotiation with their equipment and materials with the capacity to generate unexpected effects beyond the artist's control or anticipation, and

4. its association with both the evaluation of the work as a work and of the practitioner as self-validated.

In the discussion that follows, I outline the nature of the challenge articulated by participants and how this relates to flow, before considering how this challenge is localised around a specific aspect of artistic practice. I then characterise this aspect of artistic practice in terms of its material capacities, which are considered to give rise to the emotional struggle, and I go on to suggest that these material capacities lie at the heart of both artistic challenge and artistic flow experiences.

\section{Discussion}

\subsection{Negativity and challenge in flow}


The frequency of reports of exhilaration, immersion, losing track of time, and forgetting themselves indicates a high level of experience of flow across participants. However, despite the passion they have for their artwork, many of these artists related negative or unpleasant aspects of their practice. Philippa speaks of an emotional roller coaster and says that there is often a temptation to give up, while Marnie describes a fear of going on, a series of highs and lows throughout the process, and a desire to destroy her work through frustration. The profundity and intensity of these unpleasant and potentially destructive experiences is illustrated by Laura's statement that to achieve a successful work she "will have pushed myself almost with a survival instinct to find the key to make it work" (I2), while Polly likens this experience to an athlete's pain barrier, which she has to push through or "it can completely stop you from doing the work" (I1). Clearly, these are not minor incursions of negativity but are substantive features in an artistic process of varied affect that take on a sense of physical obstructiveness and jeopardise the very completion of the work.

These artists indicate that they successfully complete their works not so much in spite of these negative periods but rather by virtue of them. Katherine comments that "if you don't do the angst getting it roughly right, you're in trouble" (P1), while Laura echoes this in stating that "if a painting works, really works and is good, there will have been a stage towards the end of the process of working on it when I have decided it doesn't" (I2). Polly articulates this particularly clearly:

"I'm also beginning to realise that the fog [that] you sometimes get when you don't know where you're going is an important part of that creative process, [and] the more you do it the more you realise it's not you floundering, it's actually an important part of the process [that] you've got to push yourself through" (I1) 
and

"it's that total immersion [it's] that having time to push and push and push"

Of particular importance is Polly's association of her experience of total immersion with pushing through her equivalent of the athlete's pain barrier, which is mirrored by Susan's description of her ideal artistic experience as "a battle, because they all turn out to be a battle, every time you do anything it's a battle" (I1). For Susan, too, this period of difficulty is crucial to her optimal artistic experience. For these artists at least, the experience of flow during their practice does not preclude periods of negativity, which entail emotional dips, destructive urges, a sense of adversity, and a desire to abandon the work. Furthermore, these periods of negative valence are deemed to be crucial to both the successful accomplishment of the work, and to the experience of their practice as flow.

The second characteristic of flow brought into question by these artists' accounts is a balance between the challenge faced and the skills available to face it. Katherine's sentiment that "the angst of the drawing phase is the horribleness of not being certain of my ability to get the perspective right the proportions right and everything else" (I2) is at odds with the skillschallenge balance outlined in the flow literature and is shared by other artists. Clare talks about having "to get past the how am I going to do this" (I1) stage, while Laura describes it as being like "swaying in the middle of a rope bridge. You can't go back, you've got to keep progressing, but it's not a comfy experience" (I2) where there is "anxiety and fear of failure" (I2).

Participants' experiences of flow feature significant periods of negativity that threaten to prevent the completion of the work. These negative periods appear at least partly associated with an imbalance between the artist's perception of the challenge they face and their perceived 
skills in meeting that challenge, experienced and expressed as a need to push through the challenge to establish the sufficiency of their skills. These features of their artistic experience are seemingly deemed necessary for both the successful completion of the work and the experience of their artistic practice as flow. They are also temporally clustered around a particular period within artistic practice, during which the ontological status of the work as an artwork hangs in the balance and the artist's skills are most stretched.

\subsection{The elusive pivotal point}

The challenge and negativity identified as foundational to both the successful outcome of artistic practice and the experience of that practice as flow are concentrated around a pivotal point in the emergence of an artwork. Echoing the findings of previous research in which artists reported difficulties in determining whether the work is finished (Mace and Ward, 2002, Mace, 1997), the common challenge for these artists — what Polly calls "every artist's dilemma" (I2) - is knowing when to stop. As Marnie comments, "you can keep going and keep going and it's when to stop and that's often one of the problems that you can overwork it" (I1). The pivotal point, in this light, is the point in the evolution of an artwork at which, if artistic activity stopped, the artwork would be considered complete or successful.

Four features related to this artist's dilemma are noteworthy here. The first is a struggle against a tendency or compulsion to keep going and an associated risk of ruining the work. Marnie calls it a problem stage "where you think I'm going to have to keep at this and I'm really going to ruin it" (I2) which for her results in "a muddy mess" (P1), while Philippa comments that "it's whether I can resist doing too much to it, so least is best" (I1). These comments of Marnie and Philippa also allude to the second feature of the artist's dilemma, that there comes a stage in the development of the artwork, once that pivotal point has been passed, that the artwork becomes irretrievable. Susan talks about having to put an artwork aside if it 
doesn't work, and Katherine says that this is “a real pain because you've messed up something that up to then had potential" (I2). The third feature of the artist's dilemma is that the pivotal point may never arrive. When I asked how Susan knows when that period of difficulty is over, she replied "sometimes you don't, sometimes it isn't" (I1). The fourth feature of the artist's dilemma is that even if the pivotal point does arrive, its arrival cannot be predicted or readily identified: if it could be, the risk of overworking would not arise. Marnie comments that sometimes it's too late and you've ruined it, while Clare's testimony perhaps provides the most comprehensive account of all of these features of the artist's dilemma:

"the difficult thing is, you know, overdoing [it] so less is often more because you feel compelled to just add another mark and another mark and in the end you just disappear up your own backside so you've just made this big mess and you've lost what was nice, the things that were nice about it" (I1)

Considering these features collectively, the pivotal point might be associated with a point of no return: to a degree, undoing and reworking previous marks provides some leeway around the pivotal point, but beyond a certain stage the work is ruined and cannot be salvaged. The negative aspects of an artist's practice are seemingly concentrated around this anticipated pivotal point in the emergence of an artwork, which is considered by these participants as essential for the successful completion of the artwork, but which may or may not arrive and which cannot be predicted or readily identified. It is, I suggest, this indiscernibility of the pivotal point that brings the risk of overworking, which perhaps accounts for the depth of immersion necessary for flow, and which makes it difficult for participants to specify what constitutes 'overdoing it' (Clare) or how they determine that 'it's too late' (Marnie), leaving much work still to do to identify the form and experience of material feedback that artists 
receive from their emerging artworks. Clare's comment that "less is often more" (I1) is telling here, as it suggests a progressive reduction in the scale of adjustments made to a work as the work nears completion (Mace and Ward, 2002). As the artist grapples with this indiscernibility the need for precision increases, encouraging the use of smaller scale and less marked alterations (France and Henaut, 1994) and enhanced sensitivity and responsiveness (Ingold and Hallam, 2007) to changes in material effects and affects, although those effects and affects seemingly remain difficult to specify.

This experience of negativity therefore describes the zone of indiscernibility around the pivotal point. My use of the term zone of indiscernibility should not be confused with either the discussion of indiscernibility of two or more artworks in philosophical debates about art (for an example, see Margolis, 1998, Danto, 1999, Margolis, 2000), or with Deleuze's discussion of a zone of indiscernibility around the artistic process as a whole through which the diagram allows something to emerge (Deleuze, 2005). Instead, my conceptualisation of a zone of indiscernibility refers to a narrower episode in artistic practice, specifically orientated around the need to identify the pivotal point at which artistic activity should cease and the artwork is complete.

As indicated above, an artist's engagement with this zone of indiscernibility is also a period of instability when the artwork is neither one thing nor the other: it is chimerical during this period of instability (Banfield, 2017). It has not yet settled at a point of completion but hangs between being an incomplete series of marks on the one hand and irretrievably overworked on the other. It is only if activity ceases at the pivotal point that artworks are considered complete.

The zone of indiscernibility and period of chimerical instability suggested here are consistent with the idea that sensory indiscernibility is inescapable in artistic practice 
(Margolis, 2000), although here this sensory indiscernibility performs a specific function at a critical juncture in the evolution of an artwork. Reflecting the centrality to artistic practice of the relationship between spatial and ontological thinking (Barfield, 2006), the coincidence of the zone of indiscernibility and period of chimerical instability is also reminiscent of the heterotropic fantastic, a sense of instability and uncertainty induced by indecision at the edges of an artwork (Lebensztejn, 1994). However, my emphasis here is not on the material extremities of a physical work of art, but on the ontologically constitutive edges between a completed artwork and incomplete marks on the one hand, and an overworked mess on the other. Materially and ontologically, the indiscernibility-instability nexus potentially confuses and complicates the definition of the work as art.

The zone of indiscernibility and period of chimerical instability coincide: materially, temporally and metaphysically, but the former refers to the perceptual experience of the artist while the latter refers to the ontological status of the artwork. The pivotal point constitutes the point in the emergence of the artwork when the work is no longer a series of marks but has not yet become "a muddy mess" (P1): the point at which the artwork is complete and the indiscernibility is resolved. This would seem to be the point at which, for Merleau-Ponty, the work itself as complete and understood shows that there was something to be said (MerleauPonty, 2004a): the meaning of the work is successfully instantiated in the work. However, this point can only be reached if the artist successfully ceases activity on the artwork at the pivotal point, and based on these participants' accounts, this is negotiated materially, which reinforces the role of sensory indiscernibility in artistic practice.

\subsection{Material dialogue}

The foregoing discussion highlighted the experience of a focused period within artistic practice during which materiality affects seem particularly pertinent to artistic experience and 
outcome. To speak of material affects here is simply to recognise that materials can make a difference, impacting on human practitioners affectively, and to suggest that this is a contributing factor in the attribution of artistic control by some artists to their tools and materials identified in previous research (details removed for peer review). The material aspects of artistic practices play a significant role in their outcomes, seemingly bestowing a work of art with its own internal dynamism (France and Henaut, 1994), which might be conceived as agency. These participants' practices reflect the notion of a dialogue between an artist's concrete practices and their thinking, in which materiality talks back (Sennett, 2009, Dewey, 1934), and through which new forms and images bring possibilities of new meanings (Sullivan, 2008). Not only does the artwork, through its material affects, thereby seemingly partially determine its own outcome, but through the negotiation of these material affects, the possibilities of new meanings bring the potential for self-validation on the part of the artist. Katherine describes a sense that "something evolves in the process of doing it, so I don't always know at the outset what's going to be at the end" (I1), while Polly comments that a lot of problems "you have to solve along the way don't you it's not something you know in advance" (P2). The end goal remains the resolution of the indiscernibility but the lack of a clear path to its resolution brings both sources of challenge and opportunities for self-discovery and mastery in the search for the pivotal point, and the challenges that emerged through this material negotiation took varied forms for these participants.

For some artists the perceived recalcitrant behaviour of their materials was troublesome, such as Katherine, for whom “sometimes the paints won't give you what you want out of them, so you get a paint that's too wishy-washy, whatever you do it won't deepen" (I1) and who says that "I've never yet had the paints working perfectly [you know] they just don't, it's not in their nature" (I1). In contrast, for other artists the unpredictability of their materials brings vitality to their work, including Philippa who says: 
"you put colour into water, a watery surface, you come back after maybe the next day and all sorts of wonderful things have happened that I didn't put there it's the sort of pigments taking over [and] that is very exciting" (I1)

Similarly, artist responses to what they consider to be mistakes range from remedial steps "to cover up stuff that you don't like" (Polly, I2) to allowing the incidental and accidental factors in their practice to constitute the resulting work. Again, Philippa exemplifies this perspective:

"so that's appeared now. I could probably get most of that out and correct it but it might be quite nice as a mistake, you know part of the painting" $(\mathrm{P} 1)$

As well as illustrating various ways in which materials are considered to act back, exerting their own influence (Hennion, 1997, Hawkins, 2010, Buchli and Lucas, 2001), these different perspectives indicate general differences in the approaches of these artists to their practices. While Laura echoes Philippa's openness to the material influence of her work, describing a "process of the painting dictating to me" (I2) and "physical materials taking on their own course and showing me the next step" (I2), other participants emphasize their decision-making processes. Katherine, for example, talks about points at which she has to make fundamental decisions, and Clare says that if a piece works "it works because of the choices you've made, the decisions you've made all the way through" (I2).

This emphasis on artist decision-making seemingly contradicts the attribution of agency by some artists working in two-dimensional media to their materials (details removed for peer review). However, it is not simply a matter of whether the artist seeks to impose their will on recalcitrant materials or whether they relinquish control to those materials. Clare and 
Katherine, despite emphasizing their decision-making processes, are also alert to and appreciative of unexpected material effects and affects, as evidenced by Clare's assertion that "the thing that gives the best results I think is just [to] let yourself go" (I1). Similarly, Laura and Philippa, despite emphasizing the role of their materials, acknowledge the need for them to make decisions. For Philippa, the very unpredictable effects that she appreciates arise from her initial decision to work wet, while Laura says that she often cannot anticipate when she needs to make a decision, introducing a further source of challenge and again pointing to the interweaving of challenge and mastery in flow if that need is anticipated.

Rather than a clear dichotomy between controlling and surrendering to the artwork, the practices of these artists are characterised by negotiated agencies that can assume varied and dynamic forms, such that artist and material elements operate within a heterogeneous association (Murdoch, 1997). A brief comparative consideration of artistic practice and improvisational theatre should elucidate this point further. It has been asserted that a painter's view of their audience while they are working is very different from a fellow actor saying something unexpected and using that to find new inspiration as to where to take the work next (Sawyer, 2000). However, such a perspective equates the other actor to the audience, whereas it is equally possible to equate the other actor to the artwork. Conceptualized in this manner, there is no difference between the responsiveness of one actor to the other and that of the artist and artwork to each other. In both instances, changing patterns of convergence and divergence demand critical responsiveness that recognises multiple sites of agency (Hawkins, 2010) as experienced within these artistic practices.

Polly provides a particularly explicit account of her materials not only as agentive but also as co-operative: 
"things are beginning to work together where I feel the composition, the media, are beginning to form themselves into an image that I am beginning to enjoy and feel satisfied with" (I1)

Here, Polly positions herself as facilitator and spectator rather than creator, initiating but not controlling the artistic practice process. Interestingly, although Polly talks about an image forming, she does not mention specifics such as colour and form that we might commonly associate with imagery, and even her mention of composition is associated with the media, which suggests a tactile or textural element to the forming of the image rather than being purely visual. This is reminiscent of Merleau-Ponty's 'fabric of brute meaning' in the sensible lifeworld (Merleau-Ponty, 2004b: 293), upon which artists draw in an intertwining of vision and movement and for whom there is no distinction between touch and sight (Merleau-Ponty, 2004a, 2004b). Perhaps exemplify the artist's 'voracious vision' that opens upon a texture of being (Merleau-Ponty, 2004b) where feeling and seeing are one and the same thing, Laura describes an experience of being in her painting while she was painting it: “you're there; you're in it" (details removed for peer review). For Laura, it seems, as in flow, action and awareness are merged (Csikszentmihalyi, 1996), enabling her to experience being in the painting while she is engaged in the visual-tactile activity of materialising an image. Such accounts suggest a distinctly spatial experience of being in the painting, quite removed from everyday experiences of space and place, and perhaps a distinctly spatial quality to experiences of flow, inviting further comparative research into different flow experiences to explore these spatial qualities and experiences and to establish a fuller understanding of internal differentiation within flow experiences.

In the accounts of these artists, materials appear to be vital, generating the work's own internal dynamism (France and Henaut, 1994) and potentially generating unique spatial 
experiences. Laura comments that "I won't dictate to a painting how it should resolve itself I become a channel or a partner in the process with the painting" (I1). It is on the basis of these interactions with the work that she is pushed to make unanticipated decisions. For Laura, the dynamism of the work dictates what the artist may do (France and Henaut, 1994), and the creative power seems to lie in the artwork itself as:

“when a painting's not there I keep going back to it. I keep looking at it, it just draws me back and draws me back. I can't stop going back to it and looking at it and looking at it, searching for an answer" (I2)

For Laura, "the painting has its own reality, its own identity, and when it's good the painting and I will agree that it's good and I won't touch it again. It's done, it's finished"(I2). In effect, the painting leads Laura through the process of its emergence: "give that a go that works wow, ok where does that step take me now?" (I2). Laura plays a role by doing something in order to make something happen but she does not control what subsequently happens. Not only is it imperative for Laura not to control the something that then happens (Hennion, 2001); it is impossible to control the something that then happens because the work has its own internal dynamism and the materials their own incipient tendencies, acting independently to achieve their own specific capacities and affects (France and Henaut, 1994, Kearnes, 2003, Anderson and Tolia-Kelly, 2004, Bennett, 2010).

The accounts of these participants illustrate both artist-material interaction in artistic practice, and myriad microgenetic capabilities of artistic materialities within that interaction, which together seem to contribute to the ontological indeterminacy of the artwork during the period of chimerical instability. The former is encapsulated in heterotechnicity, a heterogeneous co-operative framework; the latter in heterochrony, the occurrence of largescale changes subsequent to small-scale variations. By considering these notions in relation to 
artistic practice, we can perhaps elucidate the complex issues surrounding the relationship between challenge and skills in artistic flow experiences.

\subsection{Heterotechnicity, heterochrony and flow}

With the artist, materials and unfolding artwork operating together, the accounts of these artists suggest a relationship of heterotechnicity: the integration of individuals into a larger cooperative framework (Reynolds, 1994). Here incorporating human and nonhuman actants, art materials are deemed to suggest ways in which artists can work with rather than on them in a collaborative process that makes present different qualities and affects in ever-changing associations (Hawkins, 2010). These participants indicate that these varied actants participate in a somewhat co-operative effort to bring the artwork to completion; to the cessation of activity at the pivotal point.

A particular feature of the materiality effects and affects in artistic practice is their ontogenetic heterochrony, a term borrowed from the biological sciences and applied to artistic practice to describe how profound changes in morphology can arise from small changes in the timings of developmental events (Kozbelt, 2009). Multiple instances of heterochrony can occur in the evolution of a single artwork, such as adding, truncating or mutating steps in the creative process. As with heterotechnicity, heterochrony emphasizes the constitutive role played by constraints from the materials themselves in structuring the artistic practice process, but unlike heterotechnicity, heterochrony changes the recipe for the process of creation itself (Kozbelt,

2009). This is consistent with Merleau-Ponty's observation that in 'working over' a favourite problem, presuppositions about other aspects of the work are upset, such that the whole work must be done again differently (Merleau-Ponty, 2004b: 320), which emphasizes the large scale impacts on an artwork that can result from small scale changes in its execution. It is this heterochronic capacity that seemingly generates much of the ontological indeterminacy and 
indiscernibility of the pivotal point, because heterochrony brings the potential for constant variation in the artistic recipe, against which context the identification of the pivotal point must take place.

There is, however, an important distinction to be drawn between ontogenetic heterochrony as applied in biology and in artistic practice. In biology the organism must remain viable throughout heterochronic changes whereas it is claimed that this is not the case for the artwork during its development as evidenced by the variation in appearance and quality over an artwork's or artist's lifetime (Kozbelt, 2009). However, the equivalence of an artwork's quality or appearance and its viability is by no means clear. Many participants described volatile emotional experiences, including Marnie's urges to destroy her work and Philippa's temptation to give up, but although they might not have been happy with the quality or appearance of the artwork at those points, the artwork is only considered nonviable once the pivotal point has been passed. An artwork that is deemed to be poor is still capable of being completed successfully until the pivotal point has been passed. Ontogenetic heterochrony allows artistic practice to change its own rules and while there is a viability limit to the changes that can be sustained, this viability limit is associated not with the appearance or quality of the work as such, but the status of the artwork in relation to its pivotal point; a point which itself changes heterochronically, thus contributing to its indiscernibility. This distinction emphasizes the ontogenetic function of heterochrony and the indiscernibility of the pivotal point, as it is the heterochronic variability (recipe mutation) that generates the indiscernibility but which must be overcome if the artwork is to be ontologically realised.

This heterochrony in the creative process can be considered to generate a constantly evolving material multiplicity with its own productive momentum; a self-transformational system of which the artist is a part (Ingold, 2011b) and in which the self-movement of the artist with and through their materials has the potential to expand their sense of self (Sheets- 
Johnstone, 2011). Immersion in this productive momentum is, I suggest, experienced by these artists as flow, a phenomenon in which their self-awareness and their perception of time are altered in a manner that makes the activity autotelic (Csikszentmihalyi, 2002) and generates a sense of practical integration with the materials of the activity which, for Laura, stimulated a radical shift in spatial experience. The challenge of responding sensorially and co-operatively to the unpredictability of material affects perhaps accounts for a loss of conscious selfawareness as participants engage with their materials more in a pre-reflective than a reflective sense (Zahavi, 1999, 2005), while the particular productive momentum of a specific artistic practice perhaps prompts a shift in temporal and spatial awareness and experience as the artist becomes entrained in its rhythm. Both the artwork as ontologically complete and the artist as self-validated seemingly come about through the material dialogue of artistic practice, in particular its heterotechnic and heterochronic capacities, which also appear to constitute conditions conducive to flow, providing challenge and stimulating immersion. Through that material dialogue it is possible for an artist to attribute agency to their materials as those materials help to determine when activity should cease, while simultaneously feeling validated as part of that bigger material co-operative through the shifts in self, spatial and temporal awareness, generating the immersion, expansiveness and mastery often associated with flow.

However, the inherent unpredictability of material effects and affects, combined with the self-transformational capacity of the heterotechnic framework means that each artistic practice experience is unique, such that previous experience does not provide assurance as to how to resolve the instability and indiscernibility in future artworks. These ambiguous tensions between artist and materials that are constantly changing in mutual responsiveness sustain both the skills-challenge uncertainty and the potential for the experience of flow from one period of artistic practice to another, stimulating repeated engagement with that practice. The high number of unpredictable actants in the heterotechnic framework, the non-predetermined ways 
in which those actants move, change and interact, and their heterochronic effects perhaps make it impossible for artists to be certain as to the relationship between the challenge they face and their skills in facing it until they have faced it. In generality then, skills must seemingly be stretched in the face of challenge in order to gain the sense of mastery attributed to flow experiences, but in particularity, the manner, degree and number of ways in which those skills are stretched varies between activities, as does the ability to perceive the challenge at hand, the skills available to face it and the nature of the relationship between the two.

Consequently, heterotechnicity and heterochrony are conceived as coming together in artistic practice to generate a period of chimerical instability and a zone of indiscernibility which these artists experience as frustrating but necessary to both the successful outcome of the work and their experience of their practice as flow, by generating a perpetually shifting source of challenge. If their skills are stretched then flow is possible and the artist is selfvalidated, and if the indiscernibility is resolved successfully then the artwork is rendered ontologically complete and the artist further validated.

\section{Conclusion}

This paper has explored artistic practices and their associated flow experiences with a view to clarifying the relationship between challenge and skill in flow. It drew on previous phenomenological psychological research that identified differences in attributions of agency between artists working in $2 \mathrm{D}$ and $3 \mathrm{D}$ media, and incorporated non-representational geographical concerns with practices, materiality and the pre-reflective to explore further the conditions for the emergence of the skills-challenge relationship in artistic flow experiences. In particular, the difficulty of determining the nature of the skills-challenge relationship during artistic practice has been explicitly drawn out due to the indiscernibility of the pivotal point 
and has been associated with material vitality in artistic practice, as meaningfully experienced in the artistic practices of these participants.

The negatively experienced emotional struggle during artistic practice, variously described as a battle or fog or rope bridge, seems at least partly determined by uncertainty regarding the ability of an artist's skills to meet the challenge that they face, and has been identified as concentrating around a pivotal point in the development of the artwork, at which cessation of activity would render the work complete and successful. During this period of chimerical instability the work is no longer merely a series of incoherent marks, yet it has not reached a point of completion, nor has it passed the point of no return after which the work is considered an irredeemable mess. The challenge for the artist is to identify the pivotal point at which the artwork is both materially and ontologically defined. However, the relationship between their skills and the challenge they face, along with the pivotal point itself, remains obscure by virtue of the myriad materialities at work in artistic practice and their multiple heterochronic effects, changing the recipe of the artwork's creation during its very creation. Resolving the instability involves material dialogue, but this dialogue is an uncertain business because the material effects and affects involved contribute to the instability and indiscernibility that must be overcome. In turn, these material capacities have been described as both constituting the challenge within the artistic practices of these participants, and potentially establishing conditions conducive to flow. If the chimerical instability is resolved successfully, the artwork is made ontologically complete whether or not the artistic practice was experienced as flow. In such cases, there might exist a balance between skills and challenge, resulting in skills not being stretched sufficiently to generate flow. Equally, flow might be experienced in the effort to resolve the chimerical instability, even if ultimately the instability is not resolved successfully, if it is the challenge arising from the material capacities that focuses attention sufficiently for conscious self-awareness to recede in favour of pre- 
reflective engagement in material dialogue. These material processes are seemingly foundational to the resultant artwork; the challenges and difficulties that they introduce are perhaps foundational to an artist's experience of flow during their artistic practice; and the negotiation of multiple materialities has potential implications for practitioner self-validation, rendering artistic practice as potentially both flow-inducing and self-transformational.

Employing non-representational geographical thinking to conceptualise and research the phenomenon of flow in artistic practice differently, this paper has brought two concepts within the context of material artistic practices (heterotechnicity and heterochrony) into productive dialogue with two notions of material and ontological determination in artistic practice (a period of chimerical instability and a zone of indiscernibility). Forging these connections has highlighted the importance of uncertainty concerning the skills-challenge relationship in some conceptions and experiences of flow; has provided an opportunity to examine one particular source of challenge in artistic practice; and has culminated in the suggestion that this very skills-challenge uncertainty lies at the heart of many artistic flow experiences by virtue of the material capacities within artistic practice. The productivity of integrating phenomenologically inspired psychological research with non-representationally oriented geographical research is evidenced by the refined conceptualisation of the source of challenge in flow and its relationship to the skills available, the methodological innovation that stretches phenomenology in a more applied direction, the more spatial conceptualization of flow experiences, and the identification of numerous avenues for further interrogation of flow and the nature and significance of the skills-challenge relationship in generating flow experiences, both within and beyond artistic practice. 


\section{References}

Anderson, B \& Harrison, P 2010, 'The promise of non-representational theories', in B Anderson \& P Harrison (eds.), Taking-place: non-representational theories and geography. Farnham, Ashgate, pp.1-34.

Anderson, B \& Tolia-Kelly, D 2004, 'Matter(s) in social and cultural geography', Geoforum, vol 35, pp.669-674.

Ash, J \& Simpson, P 2016, 'Geography and post-phenomenology' Progress in Human Geography, vol 40, pp.48-66.

Bachelard, G 2000, The dialectic of duration, Manchester, Clinamen Press.

Bakker, AB 2005, 'Flow among music teachers and their students: The crossover of peak experiences', Journal of Vocational Behavior, vol 66, pp.26-44.

Banfield, J 2016, Geography meets Gendlin: an exploration of disciplinary potential through artistic practice, New York, Palgrave Macmillan.

Banfield, J. 2017, 'Researching through unfamiliar practices', Cultural Geographies, vol 24 (2) pp.329332.

Banfield, J \& Burgess, M 2013, 'A phenomenology of artistic doing: flow as embodied knowing in 2D and 3D professional artists', Journal of Phenomenological Psychology, vol 44, pp.60-91.

Barfield, N 2006, 'Spatial ontology in fine art practice', In K Macleod \& L Holdridge (eds.), Thinking through art: reflections on art as research, London; New York, Routledge.

Bennett, J 2010, Vibrant matter: a political ecology of things, Durham, N.C., Duke University Press.

Buchli, V \& Lucas, G 2001, Archaeologies of the contemporary past, London, Routledge.

Csikszentmihalyi, M 1975a, Beyond boredom and anxiety: (the experience of play in work and games), San Francisco; London, Jossey-Bass.

Csikszentmihalyi, M 1975b, 'From problem-solving to problem-finding', in IA Taylor \& JW Getzels (eds.), Perspectives in creativity, Chicago, Aldine, pp.90-116.

Csikszentmihalyi, M 1975c, 'Play and intrinsic rewards', Journal of Humanistic Psychology, vol 15, pp.41-63.

Csikszentmihalyi, M 1991, Flow: the psychology of optimal experience, New York; London, Harper Perennial.

Csikszentmihalyi, M 1996, Creativity: flow and the psychology of discovery and invention, New York, Harper Collins.

Csikszentmihalyi, M 2002, Flow: the classic work on how to achieve happiness, London, Rider.

Csikszentmihalyi, M \& Robinson RE 1990, The art of seeing: an interpretation of the aesthetic encounter, Malibu, Calif, Getty Center for Education in the Arts.

Danto, AC 1999, 'Indiscernibility and perception: A reply to Joseph Margolis', British Journal of Aesthetics, vol 39, pp.321-329.

Deleuze, G 2005, Francis Bacon: the logic of sensation, London, Continuum.

Dewey, J 1934, Art as experience, London, Allen \& Unwin.

Dewsbury, J 2010a, 'Language and the event: the unthought of appearing worlds', in B Anderson \& P Harrison (eds.), Taking-place: non-representational theories and geography. Farnham, Ashgate, pp.147-160.

Dewsbury, JD 2010b, 'Performative, non-representational, and affect-based research', in D Delyser, S Herbert, S Aitken, M Crang \& L McDowell (eds.), The SAGE handbook of qualitative geography. Los Angeles; London, Sage, pp.321-334.

France, MM \& Henaut, A 1994, 'Art, therefore entropy', Leonardo, vol 27, pp.219-221.

Greenhough, B 2010, 'Vitalist geographies: life and the more-than-human', in B Anderson \& P Harrison (eds.), Taking-place: non-representational theories and geography. Farnham, Ashgate, pp.37-54.

Hawkins, G 2010 'Plastic materialities', in B Braun \& S Whatmore (eds.), Political matter: technoscience, democracy, and public life. Minneapolis; London, University of Minnesota Press, pp.119-138. 
Hennion, A 1997, 'Baroque and rock: Music, mediators and musical taste', Poetics, vol 24, pp.415435.

Hennion, A 2001, 'Music lovers - Taste as performance', Theory Culture \& Society, vol 18, pp.1-22.

Ingold, T 2011, The perception of the environment: essays on livelihood, dwelling and skill, London, Routledge.

Ingold, T \& Hallam, E 2007, 'Creativity and cultural improvisation: an introduction', in E Hallam \& T Ingold (eds.), Creativity and cultural improvisation. Oxford: Berg, pp.1-24.

Joseph, S \& Linley, AP 2008, 'Positive psychological perspectives on posttraumatic stress: an integrative psychosocial framework', in: S Joseph \& AP Linley (eds.), Trauma, recovery, and growth: positive psychological perspectives on posttraumatic stress. Hoboken, Wiley, pp.320.

Kaltwasser Hamilton, AK; Pernia, DM; Wilson, CP; Dell'Aquila, DC 2018, What makes meatheads happy? A phenomenological analysis of flow experiences in metal musicians, Qualitative Research in Psychology. DOI:10.1080/14780887.2017.1416210. Accessed 30 March 2018

Kearnes, MB 2003, 'Geographies that matter - the rhetorical deployment of physicality?' Social \& Cultural Geography, vol 4, pp.139-152.

Kozbelt, A 2009, 'Ontogenetic Heterochrony and the Creative Process in Visual Art: A Précis', Psychology of Aesthetics, Creativity, and the Arts, vol 3, pp.35-37.

Lebensztejn, J-C 1994, 'Starting out from the frame (vignettes)', in P Brunette \& D Wills (eds.), Deconstruction and the visual arts: art, media, architecture. Cambridge, Cambridge University Press, pp.118-140.

Lipscombe, N 1999, 'The relevance of the peak experience to continued skydiving participation: A qualitative approach to assessing motivations', Leisure Studies, vol 18, pp.267-288.

Mace, MA 1997, 'Toward an understanding of creativity through a qualitative appraisal of contemporary art making', Creativity Research Journal, vol 10, pp.265-278.

Mace, MA \& Ward, T 2002, 'Modeling the creative process: A grounded theory analysis of creativity in the domain of art making', Creativity Research Journal, vol 14, pp.179-192.

Margolis, J 1998, 'Farewell to Danto and Goodman', British Journal of Aesthetics, vol 38, pp.353-374.

Margolis, J 2000, 'A closer look at Danto's account of art and perception', British Journal of Aesthetics, vol 40, pp.326-339.

Maslow, AH 1971, 'Peak experiences in education and art', Theory into Practice, vol 10, pp.149-153. McCormack, D 2010, 'Thinking in transition: the affirmative refrain of experience/experiment', in B Anderson \& P Harrison (eds.), Taking-place: non-representational theories and geography. Farnham, Ashgate, pp.201-220

McCormack, DP 2003, 'An event of geographical ethics in spaces of affect' Transactions of the Institute of British Geographers, vol 28, pp.488-507.

Merleau-Ponty, M 2004a, 'Cezanne's doubt', In: T Baldwin (ed.), Maurice Merleau-Ponty: basic writings. London: Routledge, pp.273-290

Merleau-Ponty, M 2004b, 'Eye and Mind', In T Baldwin (ed.), Maurice Merleau-Ponty: basic writings. London: Routledge, pp.293-324

Murdoch, J 1997, 'Towards a geography of heterogeneous associations', Progress in Human Geography, vol 21, pp.321-337.

Privette, G 1983, 'Peak experience, peak performance, and flow - a comparative-analysis of positive human experiences', Journal of Personality and Social Psychology, vol 45, pp.1361-1368.

Reynolds, P 1994, 'The complementation theory of language and tool use', in KR Gibson \& T Ingold (eds.), Tools, language and cognition in human evolution. Cambridge: Cambridge University Press, pp.407-428.

Sawyer, RK 2000, 'Improvisation and the creative process: Dewey, Collingwood, and the aesthetics of spontaneity', Journal of Aesthetics and Art Criticism, vol 58, pp.149-161.

Schneider, K 2011, 'Toward a humanistic positive psychology: Why can't we just get along?' Existential Analysis, vol 22, pp.32-38. 
Sennett, R 2009, The craftsman, London, Penguin.

Sheets-Johnstone, M 2011, The primacy of movement, Amsterdam; Philadelphia, John Benjamin's Publishing Company.

Simpson, P 2009, "Falling on deaf ears': a postphenomenology of sonorous presence', Environment and Planning A, vol 41, pp.2556-2575.

Sullivan, G 2008, 'Painting as research: create and critique', in JG Knowles \& AL Cole (eds.), Handbook of the arts in qualitative research: perspectives, methodologies, examples, and issues. London: Sage, pp.239-250.

Van Manen, M 1990, Researching lived experience: human science for an action sensitive pedagogy, New York, State University of New York Press.

Walker, B \& Burgess, M 2011, 'Creating voice, creating being: An interpretative phenomenological analysis of professional jazz musicians' experiences', Existential Analysis, vol 22, pp.119-139.

Zahavi, D 1999, Self-awareness and alterity: a phenomenological investigation, Evanston, Ill., Northwestern University Press.

Zahavi, D, 2005, Subjectivity and selfhood: investigating the first-person perspective, Cambridge, Mass.; London, MIT.

Zaman, M, Rajan, MA \& Dai, Q 2010, 'Experiencing flow with instant messaging and its facilitating role on creative behaviors', Computers in Human Behavior, vol 26, pp.1009-1018. 